\title{
Consumo de oxigênio, em diferentes tensōes, por Srichodactylus petropolitanus Goeldi (Crustacea, Brachyura)
}

\author{
por
DOMINGOS VALENTÉ
}

2.0 Assisbente

\section{N D I C E}

1 - Introduçāo

2 - Métodos de trabalho

3 - Parte experimental - Consumo do oxigênio por Tr.petropolitanus

a) Influência das tensões médias

b) Influência das tensões baixas

c) Influência das tensões altas.

d) Reversāo de oxigênio pelos Trichodactylus 92

4 - Discussāo

5 - Summary

6 - Bibliografia

\section{1 - Introduçāo}

Os estudos realizados sôbre o comportamento dos Crustáceos Decápodos em relaçāo ao consumo do oxigênio sob diferentes tensões na água, indicam a falta de um ponto de vista uniforme por parte dos diversos autores que se ocuparam do assunto. Assim é que Scyllarus latus e Carcinus maenas, segundo Henze (1910, p. 265), respiram independentemente da saturaçāo do oxigênio na água. Amberson, Mayerson e Scott (1924, p. 173) verificaram que Homarus americanus e Callinectes sapidus, ao contrário, apresentam estreita dependência do consumo do oxigênio do teôr do gás na água. Os mes mos autores nas suas experiências com Palaemonenes vulgaris notaram comportamento diferente, pois êsses Crustáceos são capazes de regular o metabolismo abaixo de $50 \%$ de saturaçāo, o que quèr dizer, até êsse limite o consumo de oxigênio pelo animal independe da saturaçāo. Outros sāo os resultados de Moore. Edie. Whitley e Dakin (1912, p. 286) relativamente a Cancer e a Eupagurus, que apresentam uma independência da referida tensāo. A êste respeito são dignas de observações as referências de Hyman que, em uma boa "mise-au-point" do assunto (1929, p. 507), põe dúvidas sôbre os resultados de Moore et al. por se ter exaurido o oxigênio na água muito 
antes da terminaçāo da experiência com aquêles animais. Até aqui o material de experimentaçāo restr̂ingiu-se, preferentemente, aos crustáceos marinhos.

A questāo, porém, nāo é menos complexa quando se trata dos representantes que habitam a água doce. Assim. Astacus fluviatilis parece diminuir o consumo de oxigênio à medida que declina a saturação do gás na água, conforme as manficações de Brunow (1911, p. 215). Estas experiências foram retomadas por Hée e Bonnet (1925. p. 279) que estudaram o consumo de oxigênio por $A$. fluviatilis em concentrações que variaram de 5 a $22 \mathrm{~cm}^{3}$ de oxigênio por litro dágua e determinaram ser constante o consumo do gás entre $5 \mathrm{e} 8 \mathrm{~cm}^{3}$ mas tal consumo aumentava à medida que os animais dispunham de concentrações mais elevadas. Ainda o comportamento de um dos Macruros mais comuns dágua doce nos Estados Unidos (Cambarus immunis) foi exaustivamente estudado por Helff (1928) quanto ao ccnsumo de oxigenio por animais isolados e em grupo. Pelas conclusões de Helff vê-se que o gasto de oxigênio pelo .Cambarus independe da tensāo até $20 \%-40 \%$ de saturaçāo e que a capacidade respiratória é tanto menor quanto mais idoso for o animal. Outro ponto apenas abordado de passagem pelo autor é o referente à particularidade do Cambarus reverter oxigênio para o ambiente, quanda a saturaçāo é demasiado baixa. Trabalhos mais recentes, ainda sôbre Crustáceos de água dôce, sāo os de Kalmus (1930) e de Segaar (1935) com Potamobius (Astacus) fluviatilis. Para o primeiro destes autores, a respiraçāo do. Macruro, em limites bastante extensos, independe da lênsāo do oxigênio do meio. Haveria aqui notável influência do estado de repouso ou de movimento do animal, pois que o consumo de oxigênio se eleva de $60 \%$ quando o animal se põe em movimento. No jejum, dá-se o contrário, o animal diminui o consumo do gás. Os estudos de Segaar, bastante completos sôbre a respiraçāo do mesmo Macruro, demonstraram que numa saturaçāo muito baixa há uma inibiçāo homolateral reflexa da respiraçāo, e, em consequiência ,ocorre apnéa quando a tensāo desce abaixo da normal.

Em todos os trabalhos acima mencionados o método da dosagem do oxigênio foi o de Winkler e suas modificações, sendo que as alterações da técnica se basearam, principalmente, em manter os animais em meio líquido circulante ou estacionário.

Pelos resultados acima sumariados nota-se que a questāo do comportamento dos Crustáceos Decápodos em relação às tensões de oxigênio no meio

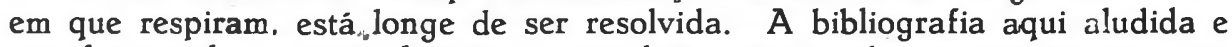
que foi aquela ao meu alcance nas condições atuais, deixa entrever que, nos representantes marinhos desta classe de Artrópodos, parece haver uma tendência para independer o consumo de oxigênio da saturaçāo do meio ambiêntc.

Nos Crustáceos de água dôce os dados fornecidos pelos vários autores nāo levam a conclusǒes definitivas. Confrontando os resultados até agora conhecidos, pode-se dizer que nêsses Decápodos há um certo grau de independência do consumo de oxigênio em relaçāo à saturaçāo da água. Ȧ vista disso, pareceu-me de importância êsse estudo nas regiões tropicais, onde a pobreza de oxigênio é um dos caraterísticos das águas dos lagos e dos poços frequentados por uma fauna numerosa e bastante variada. Assim, segui a sugestāo do Prof. Dr. Paulo Sawaya de estudar a influência da tensão do oxigênio sôbre a respiraçāo de um dos Braquiúros mais frequentes nas laǵbas e corregos dos arrebaldes de Sāo Paulo, o Trichodactylus petropolitanus Goeldi, 
baseada no comportamento dos animais em relaçāo ao consumo de oxigênio e à saturaçāo da água ambiente. Além de ser material muito favoravel para a tais pesquisas, apresenta o Tr.petropolitanus a particularidade de poder manter-se horas fora dágua, o que está a indicar contextura especial de seus sistema respiratório e, portanto, mecanismo regulador especializado. Possivelmente, como aponta Carter $(1931$, p. 16), o Trichodactylus poderá ser incluido entre os Crustáceos de respiraçāo aéria, o que em parte concorda com as observações de Lüderwaldt (1919, p. 384), que os cataloga entre os habitantes dos manguesais. Estes animais já foram objeto de pesquisas anteriores em que pude demonstrar (Valente, 1943 p. 306) sensível diminuiçāo do consumo do oxigênio quando mantidos em grupo.

A seguir, como se verá, os resultados obtidos permitem localizar ēstes Braquiúros entre os animais cujo metabolismo depende, até certo ponto, das condições de saturação do oxigênio da água em que o animal respira.

\section{Métodos de trabalho.}

Os animais eram pescados com armadilhas no rio Tieté e seus afluentes nos arredores de S. Paulo e conduzidos para o laboratório onde estacionavam em aquários com água corrente da torneira. Depois de alguns dias eram transferidos para aquários de vidro de capacidade de 3.000-5.000 $\mathrm{cm}^{3} \mathrm{com}$ água distilada. Antes de colocá-los nos aquários, era determinada a percentagem de saturação da água correspondente. Mantidos os aquários nọs laboratórios, no sub-solo, onde a temperatura não variava mais que $2^{\circ} \mathrm{C}$, verificou-se que limite de saturação de oxigênio da água distilada permanecia entre $50-70 \%$ a $19^{\circ}-20^{\circ} \mathrm{C}$. Para se obterem saturações mais elevadas, os aquários eram insuflados com exiquênio puro, conseguindo-se assim até o máximo de $222,2 \%$ de saturação. Algumas vêzes a insuflação foi feita com ar e, nêstes casos, as saturações ficavam ao redor de $90 \%$. Para as saturações abaixo de $50 \%$ foi empregado o método de deixar os animais durantue honas dentro do aquário cuja superfície era recoberta por uma camada de $5 \mathrm{cms}$. de espessura de óleo de parafina, segundo a técnica indicada por Helff (1928, p. 79) Desta maneira, foram conseguidas saturaçōes até o minimo de $29,5 \%$.

A ordem das pesquisas foi sempre a seguinte: primeirámente se determanava a percentagem de saturação da água, depois os Tr. eram previamente pesados e colocados um em cada aquário com a superfície líquida protegida por uma camada de $5 \mathrm{cms}$. de altura com óleo de parafina. A seguir, de hora em hora, geralmente a partir das $8 \mathrm{hs}$. a.m., eram feitas as demais determinações pelo método de Winkler modificado por Birge e Juday (1911, p. 13). Retiraram-se de cada vez $30-50 \mathrm{~cm}^{3}$ de água para as dosagens. Por via de regra, logo que tocava o fundo do aquário, o animal ai ficava imobilizado e assim permanecia durante todo o tempo das experiências. Geralmente, os animais experimentados haviam passado pelo menos 24 horas em jejum. Nenhum caso de muda ocorreu durante as experiências. Outros pormenores da técnica serão referidos na parte experimental correspante.

A percentagem de saturação foi determinada pela fórmula de Birge e Juday. A fim de evitar o uso do agitador dágua, vali-me do método recomendado por Sawaya (1945) que consiste em usar um sifão de vidro com a haste que mergulha no aquário perfurada em várias alturas Com isto, obtem-se água de vários extratos durante a sifonagem.

\section{Parte experimental: Consumo de oxigênio por Tr.petropolitanus.}

\section{a) Influência das tensōes médias.}

Exemplares de Tr.petropolitanus de pêsos compreendidos entre 7-11 gr. foram submetidos a diferentes percentagens de saturaçāo, sendo de $50 \%$ o valor mínimo e $68,9 \%$ o máximo iniciais nesta série de experiências. O valor mais baixo atingido foi de $43,3 \%$ nesta série de pesquisas. A maior variaçāo de tensāo entre duas horas consecutivas foi de $7,3 \%$ (exp. n. 2). A 
média dessa variação foi, pọrém, de $4 \%$ quando comparadas as tensões da primeira e da segunda hora e de $2,3 \%$ entre a da segunda e da terceira hora. Ao cabo de cada hora, nāo foi renovada a água do áquario, de modo que, em virtude do metabolismo do animal, a tensāo do oxigênio abaixou gradativamente. Os resultados acham-se expressos na tabela I.

\section{T A B E L A I}

Variação no consumo de oxigênio de Trichodactylus petropolitanus submetidos a tensão inicial média.

(Valores reduzidos a $\mathrm{O}^{\circ} \mathrm{C}$ e $760 \mathrm{~mm}$ de $\mathrm{Hg}$ )

\begin{tabular}{|c|c|c|c|c|c|c|c|c|}
\hline \multirow{2}{*}{$\begin{array}{l}\text { Expe- } \\
\text { riencia } \\
\text { N.o }\end{array}$} & \multicolumn{2}{|c|}{ Animal } & \multicolumn{2}{|c|}{ 1.a hora } & \multicolumn{2}{|c|}{ 2. a hora } & \multicolumn{2}{|c|}{ 3. s hara } \\
\hline & Sexo & $\begin{array}{l}\text { (gr.) } \\
\text { Peso }\end{array}$ & $\begin{array}{c}\text { tensão } \\
(\%)\end{array}$ & $\begin{array}{l}\text { consumo } \\
\left(\mathrm{cm}^{3} / 1 / \mathrm{h}\right)\end{array}$ & $\begin{array}{c}\text { tensरूo } \\
(\%)\end{array}$ & $\begin{array}{l}\text { consumo } \\
\left(\mathrm{cm}^{3} / 1 / \mathrm{h}\right)\end{array}$ & $\begin{array}{c}\text { tensko } \\
(\%)\end{array}$ & $\begin{array}{l}\text { consumo } \\
\left(\mathrm{cm}^{8} / 1 / \mathrm{h}\right)\end{array}$ \\
\hline $\begin{array}{r}1 \\
2 \\
3 \\
4 \\
5 \\
6 \\
7 \\
8 \\
9 \\
10 \\
11 \\
12\end{array}$ & $\begin{array}{l}\text { fem. } \\
\text { fem. } \\
\text { fem. } \\
\text { fem. } \\
\text { fem. } \\
\text { fem. } \\
\text { fem. } \\
\text { fem. } \\
\text { masc. } \\
\text { masc. } \\
\text { fem. } \\
\text { fem. }\end{array}$ & $\begin{array}{r}7,0 \\
9,0 \\
9,0 \\
9,0 \\
10,0 \\
10,0 \\
10,0 \\
10,0 \\
10,5 \\
10,5 \\
11,0 \\
11,0\end{array}$ & $\begin{array}{l}63,4 \\
60,0 \\
67,0 \\
50,7 \\
52,7 \\
66,1 \\
52,0 \\
66,3 \\
56,4 \\
68,9 \\
59,4 \\
68,3\end{array}$ & $\begin{array}{l}0,208 \\
0,471 \\
0,147 \\
0,251 \\
0,384 \\
0,147 \\
0,316 \\
0,152 \\
0,084 \\
0,161 \\
0,451 \\
0,264\end{array}$ & $\begin{array}{l}60,0 \\
52,7 \\
64,6 \\
46,7 \\
46,7 \\
63,7 \\
47,0 \\
63,9 \\
55,1 \\
66,3 \\
52,3 \\
64,0\end{array}$ & $\begin{array}{l}0,144 \\
0,164 \\
0,190 \\
0,168 \\
0,163 \\
0,076 \\
0,247 \\
0,197 \\
0,180 \\
0,250 \\
0,101 \\
0,089\end{array}$ & $\begin{array}{l}57,6 \\
50,3 \\
61,6 \\
44,0 \\
44,4 \\
62,5 \\
43,3 \\
60,8 \\
52,4 \\
62,2 \\
51,1 \\
62,7\end{array}$ & $\begin{array}{r}\overline{-} \\
0,081 \\
0,084 \\
0, \overline{120} \\
0, \overline{123} \\
0, \overline{086} \\
0, \overline{185}\end{array}$ \\
\hline
\end{tabular}

Como decorre do exame dessa tabela, os $\mathrm{Tr}$. nas condições experimentais mencionadas, consumiram mais oxigênio na primeira hora. Esse consumo decresceu sucessivamente nas horas subseqüêntes (em média: 0.253 na 1.a., 0,164 e 0.113 na 2.a e 3.a hora). Embora a variação das tensões iniciais nāo tivesse sido excessiva, entre $50,7 \%$ e $68,9 \%$, a quantidade de oxigênio consumida pelos animais variou em maior extensāo, de 0.084 e 0,471 na 1.a hora. Essa variação nāo pode correr por conta do pêso, porquanto todos os animais da experiência apresentaram pêsos próximos. $\mathrm{Na} 2$ a e na 3.a hora o mesmo fenômeno se observa, pois que as tensões oscilaram entre $46,7 \%$ e $66,3 \%$ (2.a hora) e entre $43,3 \%$ e $62,7 \%$ (3.a hora), e os consumos variaram respectivamente entre 0,076 e 0,250 (2.a hora) e 0,081 e 0,185 (3.a hora). Nota-se ainda mais que, ao cabo da 2.a hora, houve uma variação menor no cosumo do oxigênio $(0,250-0,076)$ ou sejam $16,4 \%$ em oposição a $25,3 \%$ do consumo da 1.a hora. Essa variaçāo foi ainda menor na 3.a hora $(0,185-0,081)$ correspondendo a $11,3 \%$.

Com exceção do $T r$. da experiência n. 4, em que o consumo do oxigênio foi decrescendo da 1.a para a 3.a hora, nas demais sempre houve uma alternância no consumo, 'i.é, a um menor gasto de oxigênio seguiu-se um gasto maior, seja da $1 .^{a}$ para a $2 .^{a}$ ou desta para a $3 .^{a}$ hora, e vice-versa, embora as saturações correspondentes tenham crescido continuamente.

b) Influências das tensôes baixas.

Nesta série de experiências os animais foram submetidos, logo de início, a tensões baixas, obtidas segundo a indicaçāo da p. 89 . Uma vez determi- 
nadas as concentrações iniciais do oxigênio na áqua, aqui considerada como de tensāo baixa (entre $48,8 \%$ e $29,4 \%$ ), o crustáceo era aí colocado e a seguir. em horas consecutivas, faziam-se as determinações. A temperatura oscilon enitre $19-20^{\circ} \mathrm{C}$. Foram usados animais de $10-12 \mathrm{gr}$. A maıor variaçäo de tensāo entre duas horas consecutivas foi de 4\%. Em média, entre a 1.a e a 2.a hora houve uma variaçāo de $3,1 \%$ e de $2,2 \%$ entre a 2 .a e a 3.a, e entre esta e a 4.a hora, respectivamente. Foram registrados nesta parte do trabalho quatro casos de reversāo de oxigênio pelos animais, fato que será objeto de estudo mais adeante (p. 92). A tabela II dá conta dos resultados.

\section{T A B E L A II}

Variação no consumo do oxigênio de Trichodactylus petropolitanus submetidos a tensão inicial baixa.

(Valores reduzidos a $\mathrm{O}^{\circ} \mathrm{C}$ e $760 \mathrm{~mm}$ de $\mathrm{Hg}$ )

\begin{tabular}{|c|c|c|c|c|c|c|c|c|c|c|}
\hline \multirow[b]{2}{*}{$\begin{array}{c}\text { Expe- } \\
\text { riencla } \\
\text { N.॰ }\end{array}$} & \multicolumn{2}{|c|}{$A n$ ima 1} & \multicolumn{2}{|c|}{ 1.- hora } & \multicolumn{2}{|c|}{ 2.a hora } & \multicolumn{2}{|c|}{ 3.e hora } & \multicolumn{2}{|c|}{ 4.a hara } \\
\hline & $\begin{array}{l}\text { జ్ } \\
\text { ఝू. }\end{array}$ & 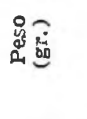 & 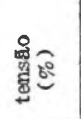 & 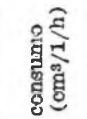 & 苟 & 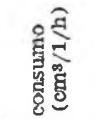 & 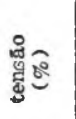 & 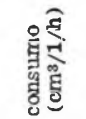 & 跑 & 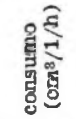 \\
\hline $\begin{array}{l}13 \\
14 \\
15 \\
16 \\
17 \\
18\end{array}$ & $\begin{array}{l}\text { fem. } \\
\text { fem. } \\
\text { masc. } \\
\text { fem. } \\
\text { fem. } \\
\text { fem. }\end{array}$ & $\begin{array}{l}10,0 \\
10,0 \\
10,5 \\
11,0 \\
12,0 \\
12,0\end{array}$ & $\begin{array}{l}47,3 \\
39,6 \\
39,6 \\
48,8 \\
35,8 \\
30,7\end{array}$ & $\begin{array}{l}0,136 \\
0.197 \\
0,191 \\
0,233 \\
0,336 y \\
0,096 y\end{array}$ & $\begin{array}{l}45,1 \\
36,2 \\
36,6 \\
45,0 \\
41,0 x \\
32,2 x\end{array}$ & $\begin{array}{l}0,225 \\
0,079 \\
0,077 \\
0,153 \\
0,165 y \\
0,171\end{array}$ & $\begin{array}{l}41,5 \\
35,2 \\
35,3 \\
42,6 \\
43,6 x \\
29,4\end{array}$ & $\begin{array}{l}0,090 \\
0,080 \\
0.153 \\
0,248 \\
-\overline{-113 y}\end{array}$ & $\begin{array}{c}40,1 \\
33,9 \\
32,9 \\
38,6 \\
31,3 \times\end{array}$ & $\begin{array}{l}= \\
= \\
=\end{array}$ \\
\hline
\end{tabular}

x - casos de reversão de oxigênio.

y - valores que, por serem de casos de reversão, não foram computados para o cálculo das médias.

Como se vê, também a partir de baixas tensões, a média dos consumos de oxigênio continuou decrescente desde a primeira hora $(0,188-0,141-0,114)$. No cômputo das médias nāo foram, naturalmente, levados em conta os casos de reversāo que constam da tabéla. A variaçāo das tensões foi de $30,7 \%$ a $48,8 \%$, e o consumo do oxigênio pelos $T r$., excetuados os casos de reversāo, manteve-se entre 0,136 a 0,230 na primeira hora. Como nas tensões médias, o pêso aqui também nāo exerce influência. $\mathrm{Na}$ 2.a hora, as tensões mantiveram-se entre $36,2 \%$ e $45,1 \%$ e o consumo entre 0,077 a 0,225 . Finalmente, na 3.a hora, para uma variação de $35,2 \%$ a $42,6 \%$ nas tensões, correspondeu uma do consumo entre 0.090 a 0,248. Tanto quanto é possível deduzir da tabéla, os animais demonstram ter capacidade de regulaçāo respiratória, porquanto, em todos os casos, exceto os de reversāo, nāo diminuiram, senāo nos valores médios, o consumo com o abaixamento progressivo da tensāo e ofereceram valores para o consumo bastante variados.

Tal como aconteceu com os $T r$. submetidos a tensões entre 50,7\% e 68.9\% (tab. I) aqui também se nota a alternância no consumo de oxigênio, i.é, a um menor gasto segue-se às vêzes um maior consumo e vice-versa. Este fenômeno é, no caso presente, mais acentuado que nos da tab. $I$. 
c) Influência das teasōes altas.

Os Tr. foram sujeitos a tensões desde $76,1 \%$ a $222,2 \%$ de saturação. A temperatura manteve-se entre $15,5^{\circ}-25,2^{\circ} \mathrm{C}$. Os animais pesavam entre 7-12,4 gr. Cumpre notar que os aquários nesta série estiveram no laboratório, onde a variaçāo da temperatura foi sensivel, o que nāo ocorreu no quarto do sub-solo, como nas experiências anteriores.

\section{T A B E L A III}

Variação no consumo de oxigênio de Trichodactylus petropolitanus submetidos a tensão inicial alta.

(Tensões expressas em percento de saturação e consumo em $\mathrm{cm}^{3} / 1 / \mathrm{h}$ reds. a $\mathrm{O}^{\circ} \mathrm{C}$ e $760 \mathrm{~mm} \mathrm{Hg}$ )

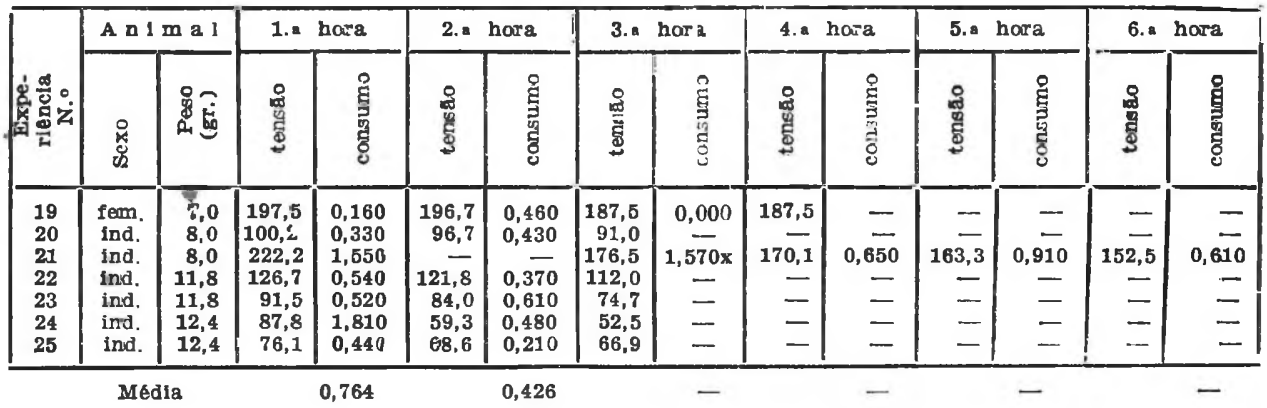

$\mathrm{x}=$ consumo referente a duas horas.

Analisando-se os dados da tabela, nos casos em que foi possível calcular a média, é patente que também aqui, o consumo foi maior na primeira hora que na subseqüente. De um modo geral, o consumo considerado pelos valores médios, embora notavelmente mais alto do que nos casos de concentrações médias, nāo está condicionado às tensões, quando analisado isoladamente. sendo inúmeros aquêles em que numa tensāo mais baixa o consumo foi mais elevado. O maior consumo verificado $(1,810)$ nāo correspondeu à maior tensāo. O que mais ressalta do exame da tabela III é o fato de o consumo médio, em altas tensões, ser quase de 3,5 vêzes maior do que em tensões médias e de 4 vêzes maior do que o das baixas tensões.

Sòmente no único caso em que foi feita a dosagem durante sete horas consecutivas é que se pode distinguir uma alternância no consumo, tal como já foi indicado nas dosagens das experiências antecedentes.

d) Reversão de oxigênio por "Trichodactylus" em baixas tensões.

Em quatro casos, todos referentes a um mesmo animal, foram registradas reversões de oxigênio ao meio ambiente. Pelo termo reversāo indico, seguindo a Helff (1. c., p. 94). os casos de, na determinação do consumo do oxígênio pelo $T r$., encontrar maior quantidade de oxigênio na água que na determinaçāo antecedente. 
T A B E L A I

Reversão de oxigênio por Trichodactylus petropolitanus sob diferentes tensð̌es.

(Valores reduzidos a $0^{\circ} \mathrm{C}$ e $760 \mathrm{~mm}$ de $\mathrm{Hg}$ )

\begin{tabular}{|c|c|c|c|c|c|c|c|c|c|c|}
\hline \multirow{2}{*}{$\begin{array}{c}\text { Imxpe- } \\
\text { rieacta } \\
\text { N.o }\end{array}$} & \multicolumn{2}{|c|}{ An $1 \mathrm{~m}$ a 1} & \multirow{2}{*}{ D a t a } & \multicolumn{2}{|c|}{$\begin{array}{l}\text { Dur. da exper. } \\
\text { (em horas) }\end{array}$} & \multicolumn{2}{|c|}{$\begin{array}{c}\text { Temper. Igua } \\
\text { (em oc) }\end{array}$} & \multicolumn{2}{|c|}{$\begin{array}{l}\text { Tensōes } \\
(\%)\end{array}$} & \multirow{2}{*}{ 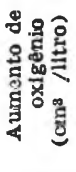 } \\
\hline & 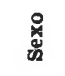 & $\begin{array}{l}\text { 品 } \\
\text { a }\end{array}$ & & 芫 & 息 & $\frac{\vec{J}}{\tilde{\Xi}}$ & $\begin{array}{l}\overrightarrow{\varpi 灬} \\
\text { 崫 }\end{array}$ & $\frac{\bar{\sigma}}{\frac{\mathrm{\sigma}}{\Xi}}$ & 黜 & \\
\hline 17 & fem. & 12,0 & 5.3.45 & 9,00 & 10,00 & 19,5 & 19,5 & 35,8 & 41,0 & 0,336 \\
\hline 17 & fem. & 12,0 & 6.3.45 & 10,00 & 11,00 & 19,5 & 19,5 & 41,0 & 43,6 & 0,168 \\
\hline 18 & fern. & 12,0 & 6.3 .45 & 8,40 & 9,40 & 19,9 & 19,0 & 30,7 & 32,2 & 0,096 \\
\hline 18 & ferm. & 12,0 & 6.3 .45 & 10,40 & 11,40 & 19,0 & 19,0 & 29,4 & 31,3 & 0,113 \\
\hline
\end{tabular}

Pelos dados da tabéla vê-se que a maior reversāo nāo corresponde à menor tensāo inicial da experiência. Importante, contudo, é frisar que os casos de reversāo se passaram todos com o mesmo animal, em baixas tensões e ocorreram em sucessāo cronológica (exp. n. 17 e 18)

\section{Discussāo.}

Pelos resultados das experiências realizadas, nota-se que Tr.petropolitanus quando submetido às tensões altas, médias e baixas de oxigênio, apresenta comportamento que varia de acôrdo com o têor da saturaçāo do gás na água.

Nas tensões médias a variaçāo do consumo foi de tal ordem em relaçāo às percentagens de saturação do oxigênio na água, que se pode dizer que o consumo de oxigênio, em tais condições, independe, sob certos aspectos, das tensões. Todavia, os dados das experiências indicam que os $T_{r}$., em geral, diminuem, quando se levam em conta apenas os valores médios, o consumo do oxigênio da primeira para a terceira hora, não obstante haver casos de maior consumo na segunda. Digno de nota, quando se consideram os casos isoladamente, é a verificaçāo da alternância do consumo, quer dizer, a um consumo mais baixo numa determinada hora segue sempre um mais alto e vice-versa. Tais fenômenos sāo indicativos de uma capacidade de regulaçāo respiratória por parte dos $T r$. Os mesmos fenômenos sāo observáveis quando os animais se encontram em meio de baixas tensões de oxigênio. Nêsses casos, porém, o decréscimo do consumo do oxigênio é mais uniforme, como se vê pela comparaçāo dos dados das tabélas I e II. A tensāo mais baixa de oxigênio conseguida foi de $29.4 \%$, a qual se revelou insuficiente para determinar a perda da capacidade regulatória, e subseqüente asfixía do animal. Talvez êsse fato corra por conta da capacidade excepcional que o $T r$. apresenta de reverter o oxigênio ao meio ambiente. Não me foi possível, nesta série de experiências, obter tensões inferiores a $29.4 \%$ a fim de determinar o limite inicial daquela reversāo.

Quanto às tensões altas, os Tr., em geral, aumentam o consumo do oxigênio com o aumento das tensões. Porém, tal aumento nāo se dá integralmente proporcional às tensões, pois que é bastante variavel, havendo mesmo 
casos de, em tensões menores, dar-se um consumo maior. Na média, todavia, pode-se dizer, à vista dos dados da tabela III, que o consumo correspondente é cêrca de 3.5 vêz:es mais que nas condições das tensões da tabela I. Isto se verifica, devo acentuar, para a primeira hora em que, também aqui nas altas tensões, o consumo é sempre maior. Pela tabela III nota-se que nas condições de supersaturaçāo o consumio de oxigênio é bastante elevado, o que estaria a indicar uma certa dependência da tensāo. Nāo resta dúvida, se compararmos os dados das três tabélas no seu conjunto, que os Tr., à medida que dispõem de maior quantidade de oxigênio gastam mais o gás, e, vice-versa, quando o meio ambiente se empobrece desse gás os animais restringem o seu consumo, até o limite de, para equilibrarem as tensões, os $T r$. emitirem o oxigênio de reserva. Isto quer dizer que, embora haja variaçāo do consumo nas diversas tensões do gás na agua, ocorre un certo rítmo de consumo do gás pelo animal. Com a designaçāo de ritmo de consumo desejo indicar o fenômeno que se percebe muito bem quando, à vista dos valores médios em cada hora - consumo vai crescendo à medida que as tensões vāo aumentando, isto é, maior quantidade de oxigênio é posta à disposiçāo do animal. Em virtude, porém, da nāo correspondência absoluta entre o consumo de oxigênio e as tensões em cada uma das séries de tensões (baixas, médias e altas) tal dependência é apenas parcial. Tenho para mim que êste fenômeno se explica pela capacidade que os $T r$. possuem de regular o consumo do oxigênio. Tanto assim que, quando as tensões sāo muito baixas, os $T r$. procuram restabelecer o equilíbrio ao mesmo tempo diminuindo o consumo e revertendo o oxigênio para o meio ambiente.

A reversāo do oxigêmio nos Crustáceos foi assinalada por Helff (1928. p. 94) em Cambarus immunis ao notar a libertaçāo de oxigēnio na água do animal, quando as tensões do gás eram muito baixas. Helff atribui o fenômeno á possibilidade de uma perda temporária ao poder das células de reterem uma reserva suplementar de oxigênio. Acentúa que, uma vez surgida a reversāo num animal, há maiores possibilidades de ela aparecer novamente, em especial quando se inicía a asfixia. Nāo posso dizer que a sugestāo de Helf́ nāo seja aceita para o Crustáceo objeto de suas investigações. Aqui, porém, em Trichodactylus, parece-me que a reversāo nāo se dá por uma perda temporária do poder de retençāo do oxigênio pelas células do corpo, mas a meu vêr, o fato dêstes Braquiúros serem capazes de respiraçāo aéria, está a indicar talvez uma possibilidade de manterem, na câmara branquial, ar de reserva, o qual seria expulso no instante necessário quando o desequilibrio se estabelecesse por causa das tensões baixas. Penso que assim se explicaria o fato de encontrar-se, num determinado momento, maior quantidade de oxigênio, que na dosagem antecedente. $E^{\prime}$ possivel também que existam em Tr. petropolitanus os lagos sanguíneos abaixo do epitélio vascular da câmara branquial, tal como Carter $(1931$, p. 16), em rápida nota, assinala em Tr. orbicularis. Se assim for, a hipótese de ser o oxigênio liberto da massa do sangue quando as tensões decrescem, deverá ser também lembrada, uma vez que êste fato nāo é raro ocorrer nos Crustáceos, como bem o demonstrou Segaar (1935, p. 502) em Astacus fluviatilis. Diz êste autor que o fenômeno está relacionado com o que chama inibiçāo homolateral reflexa da respiraçāo, i.é, o mecanismo de ventilaçāo diminui ou cessa os seus movimentos quando a tensāo decresce abaixo de certo nível, tanto no meio externo como no interno (interior do animal, portanto o sangue) 
Embora seja o meu material bastante diferente do de Helff, a semelhança dos métodos adotados e os resultados obtidos podem permitir um confronto visto como, em algumas vêzes, me foi possível confirmar as deduções dêsse autor. Assim é que, tanto $T r$. petropolitanus como C. immunis respiram mais na primeira hora que na segunda e mais nesta que na terceira, isto se se levarem em conta apenas os valores médios obtidos ( $v$. tabelas I, II, III). Helff atribui êste fato ao aumento de temperatura cada vez maior da água nas horas sucessivas. No meu caso, porém, tendo trabalhado, quase sempre, em ambiênte em que a temperatura apenas variava de $1-2^{\circ}$ durante todo o curso das experimiências, nāo é possível dar essa interpretação ao fenômeno. Quero crêr se deva antes levá-lo à conta do fato de passarem os animais da água corrente da torneira para a água distilada. Seria possível também responsabilisar o fenômeno por uma influência de $\mathrm{pH}$, pois que em geral a água da torneira tinha um $\mathrm{pH}$ por volta de 8 , enquanto que a água distilada o apresentava entre 6 e 6.5. Além disso, julgo que o fato de, na primeira hora, os $T r$. terem à sua disposiçāo maior quantidade de oxigênio, nāo é sem importância para a explicação do referido fenômeno. Ainda mais, Helff julga que o pêso dos Cambarus tem influência no consumo do oxigênio, pois os animais mais velhos, portanto mais pesados, sāo menos capazes de regular a respiraçāo. O mesmo nāo posso afirmar quanto ao $T r$., visto como nenhum efeito observei quanto ao pêso dos animais, com referência à capacidade de regulaçāo.

Das experiências efetuadas decorre a verificaçāo de possuirem os $T r$. uma capacidade de regulaçāo da respiraçāo. Quanto ao mecanismo regulador, sua identificaçāo exige outras experiências que ainda nāo me foi possível realizar. Lembro apenas que para Segaar (1.c.) a regulaçāo respiratória de Astacus fluviatilis é um fenômeno reflexo dependente das tensões baixas dos meios interno (do animal) e externo, e da ventilaçāo pelo escafognatito. No meio interno do animal tanto Segaar (1. c.) como Kalmus (1930, p. 755) assinalam a hemocianina como elemento de importância para a regulaçāo respiratória.

Finalmente, os resultados agora conseguidós com $T r$. petropolitanus submetidos às diferentes tensões de oxigênio, podem ser assim sumariados:

1 Quando Tr.petropolitanus é submetido em ambiente confinado a diferentes percentagens iniciais de saturaçāo do oxigênio na água, o consumo do gás durante a primeira hora é sempre maior, em média, que os das horas subseqüentes.

2. Em certos casos ocorre uma alternância no consumo do oxigênio, a saber, ao maior consumo segue-se um abaixamento, e a êste novamente um aumento do consumo.

3. Dentro dos limites estabelecidos para as tensões chamados altas, médias e baixas, o consumo do oxigênio por Tr.petropolitanus é bastante varíavel, mas, tomando-se como referência o consumo médio dentro de uma mesma série de tensões, os $T r$. mostram evidente dependência parcial do consumo da tensāo do oxigênio do meio ambiente.

4. Tr.petropolitanus apresenta o fenômeno chamado da reversāo do oxigênio, i.é, quando as tensões do oxigênio decrescem acentuadamente (em tomo de $30 \%$ de saturaçāo) o animal expulsa oxigênio do corpo, na ten- 
tativa de restabelecer a tensāo minima necessária para possibilitar a respiraçāo.

5. O fenômeno da reversâo é discutido no presente trabalho.

6. Os pêsos dos animais nāo influem sôbre o consumo do oxigênio.

\section{Summary}

\section{THE EFFECT OF OXYGEN TENSION ON OXIGEN CONSUMP- TION IN Trichodactylus petropolitanus GOELDI (Crustacea, Brachyura)}

The relation of oxygen consumption to oxygen tension has been determined in Trichodactylus petropolitanus Goeldi, the common water crayfish living in the streams of the outskirts of S. Paulo.

The animals were collected and brought to the laboratory were they spend from two to four days before the beginning of the experiments.

Oxygen consumption per hour was determined by the Birge and Juday's (1911) modification of the Winkler method. Only single animals were tested. $3.000-5.000 \mathrm{~cm}^{3}$ glass jars were filled with distilled water and the surface protected with $5 \mathrm{~cm}$ high column of vaseline oil. Suitable outlet tubes were employed as indicated by Sawaya (1945). Several jars have been placed in the laboratory-room where the variation of the temperature did not vary more than $2^{\circ} \mathrm{C}$.

The high oxygen tensions were obtained by insufflation of pure oxygen into the water. To secure water of low oxygen tension Helff's method (1928. p. 79) was employed. The oxygen tensions between 76,1 to 222,$2 ; 50,7$ to 68,3 and 47,3 to 29,4 were considered high, moderate and low tension respectively.

The experiments were usually started at 8:00 a.m.. and the oxygen consumption determinations were made at the end of each hour thereafter. The samples were drawn from the flasks and immediately titrated to avoid possible errors due to standing. For the titration $30-40 \mathrm{~cm}^{3}$ samples were drawn each hour. The water drawn was not replaced by water of any tension. In this way the oxygen tension lowered at each hour.

When placed into the jars filled with distilled water $T r$. remained inactive at the bottom during all the time of the experiments. $T r$. are very sensitive to light, so the jars were placed into an under-ground room where deam light and constant temperature were favourable to the animals. These were weighed before each series of experiments. The oxygen consumption was calculated in $\mathrm{cm}^{8} /$ liter/hour.

In a previous work (Valente 1943, p. 306) it was stated that the animals show considerable variation of the oxygen consumption.

No case of moult was observed during the course of these experiments.

The results from three series of tests, with $T r$.petropolitanus submitted to high (Table III) moderate (Table I) and low tensions (Table II) may be summarised as following:

1. The oxygen consumption of Trichodactylus petropolitanus has been studied at different oxygen tensions. For the majority of tested animals the 
amount of oxygen consumption during the first hour is greater than that consumed during the following hours. The average computed of the oxygen consumption of the first hour is allways greater than in the following.

2. In some cases there is relatively high and low amounts of oxygen consumption on alternate hours.

3. The variation in oxygen consumption of animals tested hourly in water of each series of experiment of determined oxygen tension is very high. However, as an average, in the same series the variation of oxigen consumption indicated that $T_{r}$. is not entirely independent of the oxygen tensions.

4 In four cases $T t$. submitted at low oxygen tensions (about 30\%) appeared pratically to stop respiration, and the tests for such periods indicated and increase of the oxygen of the water, presumably released by the animal. This phenomenon is called reversal of oxygen and it is presumed that $T r$. adds oxygen to the water, probably in order to re-establish the oxygen tension.

5. The reversal of oxygen to water by $T r$. seems due to some peculiarities of the respiratory system of this crayfish. Tr.petropolitanus lives in waters of low oxygen tensions and is able to remain out of water during a period of 24 hours, more or less.

6. Weight and age of $T r$. have no influence on variation of oxygen consumption.

\section{B I B L IO G R A F I A.}

1 - AMBERSON, W. R., Mayerson, H. S. \& Scott, W. J. - (1924-25) - The influence of oxygen tension upon the metabolic rate in invertebrates. - Jour. Gen. Physiol., v. 7. pp. 171-176. New York.

2 - BIRGE, E. \& Juday, C. (1911) - The inland lakes of Wisconsin - Wiscons. Geol $\mathcal{E}$ Nat. Hist. Surv. Bull. v. 22. Ser. Scient. n. 7, 250 pp. Madison.

3 - BRUNOW, H. (1911) - Dex. Hungerstoffwechsel des Flusskrebses. - Zeitsch. f. allg. Physiol., v. 12, pp. 215-276. Berlim.

4 - CARTER, G. S. (1931) - Aquatic and aerial respiration in animals. - Biol. Rev., v. 6 , n. 1 , pp. $1-35$. Cambridge.

5 - HEE, A. E Bonnet, R. (1925) - Influence de la teneur en oxygème du milieus sure Pintensité respiratoire des anímanx poikilothermes et des végétaux. - Arch. Internat. Physiol., v. 25, pp. 279-290. Liége.

6 - HELFF, O. M. (1929) - The respiratory regulation of the craytish, Cambarus immunis. - Physiol. Zool., v. 1. pp. 76-96. Chicago.

7 - HENZE, M. (1910) - Über den Einfluss des Sauerstoffdrucks auf den Gaswechsel einiger Meerestiere. - Biochem. Zeitsch, v. 26, pp. 255-278. Berlim.

8 - HYMAN, L. H. (1929) - The effect of oxygen tension on oxygen consumption in Planaria and some Echinoderms. - Physiol. Zool., v. 2. pp. 505-533. Chicago.

9 - KALMUS, H. (1930) - Untersuchungen über die Atmung des Flusskrebses Potamobius astacus Leach. - Zeitschr. vergl. Physiol., v. 12, pp. 725-759. Berlim.

10 - LUEDERWALDT, H. (1919) - Os manguesaes de Santos. - Rev. Mus. Paul., v. 11, pp. 309-409. São Paulo.

11 - MOORE, B., Edie, E. S., Whitley, E. \& Dakin, W. J. (1912) - The nutrition and metabolism of marine animals in relationship to (a) dissolved organic matter and (b) petticulate organic matter of sea-water. - Biochem. Jour., v. 6, pp. 255-296. London.

12 - SAWAYA, P. (1945) - Eficácia da camada de oleos vegetais e minerais como agente de proteção contra o oxigênio do ar. - Bol. Fac. Fil., Ciên. Letr., Zoologia 10, no prélo.

13 - SEGAAR, J. (1935) - Die Atmungsbewegungen von Astacus fluviatilis, - Zeitsch. vergl. Physial., v. 21 , pp. 492-515. Berilm.

14 - VALENTE, D. (1943) - O efeito de número sôbre o consumo de oxigênio por Crustáceos Decápodos. - Bol. Fac. Fil. Ciênc. Letr. Univ. S. Paulo, v. XXXII, Zool. n. 7, pp. $305-310$ S. Paulo. 